\title{
INTERNATO EM CLÍNICA MÉDICA - O PRONTO ATENDIMENTO COMO ATIVIDADE
}

\author{
Elizabeth Xavier Bianchini" \\ Paulo Tadeu Romagna Cavalheiro**
}

Unitermos: Ensino Médico, Internato, Internato em Clínica Médica, Pronto Socorro, Urgência em Clínica Médica.

\section{Resumo}

Os autores analisam os relatórios dos plantōes realizados pelos alunos internos de Clinica Médica no Serviço de Pronto Atendimento (SPA) do Hospital Universitário da Santa Maria (HUSM), no periodo de janeiro de 1984 a dezembro de 1985. Os caphulos da Classificação Internacional de Doenças com maior incidência, nos 13.328 diagnósticos, foram "Doenças do aparelho respiratório" (2.055 casos, 15,4\%), "Sintomas, sinais e afecçōes mal definidas" (1.951 casos, 14,64\%), "Lesōes e envenenamentos" (1.701 casos, 12,76\%), Doenças do aparelho circulatório" (1.247 casos, $9,36 \%$ ).

Infecçð̄es respiratórias agudas ( 1.120 casos, $8,40 \%$ ), hipertensão (508 casos, $4,35 \%$ ) e distúrbios mentais não psicóticos (522 casos, 3,92\%) foram as doenças predominantes.

Cada interno realizou, em média, 13,87 horas de plantão semanalmente.

A maioria dos atendimentos não caracterizaram situaçōes de urgência; muitos diagnósticos foram indefinidos; salientam que os doutorandos necessitam adequado preparo em Medicina de Urgência e que o SPA do HUSM necessita se adequar a sua realidade.

\section{Introduçāo}

As normas que regem o Internato Médico no Brasi|li, visam a formação do médico geral e evitam a especialização precoce, ainda no curso de graduação. Com esse objetivo, os alunos internos devem passar pelas áreas de CIfnica Médica, Cirurgia, Pediatria e Tocoginecologia.

$\mathrm{Na}$ Universidade Federal de Santa Maria (UFSM), - Internato Curricular no Departamento de Clínica Médica (DCM) apresenta em seu programa uma série de atividades, entre as quais estão os plantōes no SPA do HUSM, visando permitir aos alunos adquirir experiência em Medicina de Urgência, especialmente na área de Clínica Médica.

No presente trabalho, apresenta-se um apanhado geral sobre esta atividade no Internato em Clínica Médica (ICM) no perfodo de janeiro de 1984 a dezembro de 1985.

\footnotetext{
- Aluna do $11^{9}$ semestre do Curso de Medicina da Universidade Federal de Santa Maria

** Professor-Assistente de Departamento de Clínica Médica do Curso de Medicina da Universidade Federal de Santa Maria. Coordenador do Intermato em CM no perfodo 1983/85.
}

\section{Material e Métodos}

De janeiro de 1984 a dezembro de 1985, 5 grupos de alunos realizaram plantōes do SPA do HUSM, havendo um periodo de meados de maio a meados de agosto de 1984 em que os plantōes não ocorreram por haver greve na UFSM. O primeiro grupo constou de 16 alunos da turma de formandos de junho de 1984 (grupo 84J) e com perłodo de estágio previsto para 60 dias no DCM. O segundo grupo constou de 39 formandos de dezembro de 1984 (grupo 84D) e com estágio do DCM previsto para cerca de 90 dias. O terceiro grupo, de 12 formandos de junho de 1985 (grupo 85J) e com perfodo de estágio previsto para cerca de 90 dias. $O$ quarto grupo, de 33 alunos fomandos de dezembro de 1985 (grupo 85D) e com estágio no DCM previsto para 60 dias. $O$ quinto grupo constou de 28 alunos formandos de junho de 1986 (grupo 86J), com estágio no DCM previsto para 60 dias. Os grupos $84 \mathrm{~J}, 84 \mathrm{D}, 85 \mathrm{~J}, 85 \mathrm{D}$ e $86 \mathrm{~J}$ foram divididos em $4,5,4,3$, e 2 subgrupos (84J-1 a $84 \mathrm{~J}-4 ; 84 \mathrm{D}-1$ a $84 \mathrm{D}-5 ; 85 \mathrm{~J}-1$ a $85 \mathrm{~J}-4$; $85 \mathrm{D}-1$ a $85 \mathrm{D}-3$; $86 \mathrm{~J}-1$ e $86 \mathrm{~J}-2$ ), respectivamente, conforme o perlodo de estágio.

As diversas atividades destes grupos de alunos, incluindo os plantōes, foram distribuidos de modo a atingir a carga horária em torno de 45 (quarenta e cinco) horas semanais de atividades por aluno.

Em cada plantão o aluno preenchia uma ficha-relató rio padrão em que anotava a data do plantão, o número de horas de plantão, o diagnóstico dos pacientes atendidos, devendo receber a assinatura do médico plantonista, servindo, assim, como relatório da atividade e também como comprovante de presença do aluno. Os pacientes eram atendidos pelos doutorandos sendo supervisionados pelo médico plantonista.

A análise de todos os relatórios dos plantões realizados pelos doutorandos de janeiro de 1984 a dezembro de 1985 , permitiu saber a carga horária desempenhada pelos alunos nesta atividade e os diagnósticos mais freqüentes entre os pacientes atendidos pelos doutorandos.

Usou-se a Classificação Internacional de Doenças (CID), para a divisão dos diagnosticos por grupos ${ }^{4}$.

Os achados se referem exclusivamente aos casos atendidos pelos doutorandos de Clínica Médica.

\section{Resultados}

A Tabela I mostra que os alunos do grupo $84 \mathrm{~J}$ desempenharam uma média de $26,26 \mathrm{~h}$ de plantăo por semana de estágio do DCM, os do grupo 84D, 16,54h; os do grupo $85 \mathrm{~J}, 10,84 \mathrm{~h}$; os do grupo $85 \mathrm{D}, 10,92 \mathrm{~h}$ e os do grupo $86 \mathrm{~J}$, $10,23 \mathrm{~h}$. 
Levando-se em conta o número de alunos, os dias de estágio e o número total de horas de plantōes chegou-se à média ponderada de 13,87 horas semanais de plantão por aluno.

A Tabela I mostra ainda que nem todas as turmas tiveram o período de estágio com a duração inicialmente prevista.

Os pacientes atendidos levaram a um total de 13.328 diagnósticos elaborados pelos doutorandos. A Tabela II mostra a relação dos diagnósticos mais freqüentes, segundo a CID.

Pelo vasto número de patologias, são apresentadas apenas aquelas com incidência maior do que 30 (trinta) vezes.

\section{Comentários}

Não há normas estabelecidas sobre quais as atividades que devem compor um programa de Internato em Clinica Médica, nem qual a carga horária de cada uma delas.

Achamos que 12 a $24 \mathrm{~h}$ semanais de plantảo estāo mais de acordo com a realidade do mercado de trabalho que os médicos recém-formados encontram, devendo servir como carga horária básica no Internato e, nos anos seguintes, sofrer análise adequada de sua validade.
O perfodo de estágio encurtado de vários subgrupos ocorreu, principalmente, devido à greve ocorrida nas universidades do Brasil, em 1984, o que levou a modificaçōes no calendário escolar previamente estipulado.

Os dados mostrados na Tabela II dão idéia dos diagnósticos mais freqüentes. Dos 13.328 diagnósticos, 1932 $(14,50 \%)$ estāo no capftulo "Sintomas, Sinais e Afecçōes Mal Definidas" da CID. Isto se explica pela real dificuldade que existe em se fazer um diagnóstico num primeiro atendimento, acrescida da pouca experiência dos doutorandos em Medicina de Urgência. Tal fato demonstra a necessidade de um planejamento adequado para o atendimento destes pacientes. Uma atenção especial à triagem no serviço de emergência nos moldes preconizados por Gross e Fox ${ }^{6}$, poderia ser de utilidade no HUSM.

Os achados mostram ainda que o SPA do HUSM funciona mais como um grande ambulatório geral do que um serviço de pronto atendimento, pois a maioria dos diagnósticos nảo caracterizam emergências. Isto se deve provavelmente ao fato de haver maior procura do que oferta de consultas nos ambulatórios do HUSM onde o número de consultas é limitado; em contrapartida, não há limites para atendimento no SPA.

TABELA I - Grupos de alunos, carga horária e periodos de estágio

\begin{tabular}{|c|c|c|c|c|c|c|c|c|}
\hline GRUPO & $n A$ & $\mathrm{CHT}$ & MED/A & MIN & MAX & CHSIA & $\mathrm{DE}$ & PERIODO \\
\hline $\begin{array}{l}84 J-1 \\
84 J-2 \\
84 J-3 \\
84 J-4 \\
84 J\end{array}$ & $\begin{array}{r}8 \\
6 \\
2 \\
1 \\
16\end{array}$ & $\begin{array}{r}1126 \\
1056 \\
216 \\
144\end{array}$ & $\begin{array}{l}140.75 \\
176.00 \\
108.00 \\
144.00\end{array}$ & $\begin{array}{r}84 \\
108 \\
108 \\
144\end{array}$ & $\begin{array}{l}204 \\
204 \\
108 \\
144\end{array}$ & $\begin{array}{l}16.42 \\
20.53 \\
22.24 \\
25.20 \\
20.26\end{array}$ & $\begin{array}{l}60 \\
60 \\
34 \\
40\end{array}$ & $\begin{array}{r}2 / 1-1 / 3 / 84 \\
2 / 3-30 / 4 / 84 \\
2-10 / 5 ; 3 / 8-6 / 9 / 84 \\
22 / 9-31 / 10 / 84\end{array}$ \\
\hline $\begin{array}{l}84 D-1 \\
84 D-2 \\
84 D-3 \\
84 D-4 \\
84 D-5 \\
84 D\end{array}$ & $\begin{array}{r}9 \\
2 \\
10 \\
9 \\
9 \\
39\end{array}$ & $\begin{array}{r}1908 \\
102 \\
1962 \\
1317 \\
854\end{array}$ & $\begin{array}{r}212.00 \\
51.00 \\
196.20 \\
146,33 \\
94.89\end{array}$ & $\begin{array}{r}174 \\
48 \\
174 \\
126 \\
72\end{array}$ & $\begin{array}{r}258 \\
54 \\
222 \\
162 \\
126\end{array}$ & $\begin{array}{r}16.67 \\
8.93 \\
17.17 \\
17.36 \\
16.61 \\
16.55\end{array}$ & $\begin{array}{l}89 \\
40 \\
80 \\
59 \\
40\end{array}$ & $\begin{array}{r}2 / 1-31 / 3 / 84 \\
1 / 4-10 / 5 / 84 \\
1 / 4-10 / 5 ; 13 / 8-21 / 9 \\
22 / 9-19 / 11 / 84 \\
22 / 11-31 / 12 / 84\end{array}$ \\
\hline $\begin{array}{l}85 J-1 \\
85 J-2 \\
85 J-3 \\
85 J-4 \\
85 J\end{array}$ & $\begin{array}{r}12 \\
11 \\
7 \\
6 \\
36\end{array}$ & $\begin{array}{r}2016 \\
1326 \\
870 \\
582\end{array}$ & $\begin{array}{r}168.00 \\
120.55 \\
124.29 \\
97.00\end{array}$ & $\begin{array}{r}132 \\
108 \\
96 \\
72\end{array}$ & $\begin{array}{l}180 \\
132 \\
192 \\
120\end{array}$ & $\begin{array}{r}12.78 \\
9.48 \\
9.56 \\
10.95 \\
10.84\end{array}$ & $\begin{array}{l}92 \\
89 \\
91 \\
62\end{array}$ & $\begin{array}{r}1 / 10-31 / 12 / 84 \\
2 / 1-31 / 3 / 85 \\
1 / 4-30 / 6 / 85 \\
1 / 7-31 / 8 / 85\end{array}$ \\
\hline $\begin{array}{l}85 D-1 \\
85 D-2 \\
85 D-3 \\
85 D\end{array}$ & $\begin{array}{r}16 \\
15 \\
2 \\
33\end{array}$ & $\begin{array}{r}2496 \\
1806 \\
300\end{array}$ & $\begin{array}{l}156.00 \\
120.40 \\
150.00\end{array}$ & $\begin{array}{r}120 \\
72 \\
120\end{array}$ & $\begin{array}{l}174 \\
150 \\
180\end{array}$ & $\begin{array}{r}12.27 \\
9.26 \\
12.50 \\
10.92\end{array}$ & $\begin{array}{l}89 \\
91 \\
84\end{array}$ & $\begin{array}{r}2 / 1-31 / 3 / 85 \\
1 / 4-30 / 6 / 85 \\
1 / 10-20 / 12 / 85\end{array}$ \\
\hline $\begin{array}{l}86 \mathrm{~J}-1 \\
86 \mathrm{~J}-2 \\
86 \mathrm{~J}\end{array}$ & $\begin{array}{l}15 \\
13 \\
28\end{array}$ & $\begin{array}{l}1644 \\
1128\end{array}$ & $\begin{array}{r}109.60 \\
86.77\end{array}$ & $\begin{array}{l}60 \\
48\end{array}$ & $\begin{array}{l}180 \\
216\end{array}$ & $\begin{array}{r}9.46 \\
11.13 \\
10.23\end{array}$ & $\begin{array}{l}92 \\
61\end{array}$ & $\begin{array}{r}1 / 8-31 / 10 / 85 \\
1 / 11-31 / 12 / 85\end{array}$ \\
\hline 'GLOBAL & 124 & & & & & 13.87 & & $2 / 1 / 84-31 / 12 / 85$ \\
\hline
\end{tabular}

$\mathrm{CHT}=$ carga horária total

$\mathrm{nA}=$ número de alunos

MED/A = carga horária média por aluno

MIN = menor carga horária no grupo

MAX = maior carga horária no grupo

CHS/A = carga horária média mensal por alurio

$\mathrm{DE}=$ dias de estágio 
TABELA II - Distribuição dos diagnósticos pelos grandes

capítulos da Classificação Internacional de Doenças

13328 atendimentos (janeiro/84 - dezembro/85)

\begin{tabular}{clrr}
\hline \multicolumn{2}{c}{ Capftulos } & Casos & $\%$ \\
\hline VIII & Doenças do Aparelho Respiratório & 2055 & 15.42 \\
XVI & Sintomas, Sinais e Afecçōes Mal Definidas & 1951 & 14.64 \\
XVII & Lesōes e Envenenamentos & 1701 & 12.76 \\
VII & Doenças do Aparelho Circulatório & 1247 & 9.36 \\
IX & Doenças do Aparelho Digestivo & 1232 & 9.24 \\
X & Doenças do Aparelho Gênito-Urinário & 1073 & 8.05 \\
XIII & D. do Sist. Osteomuscular e Tec.Conjuntivo & 964 & 7.23 \\
XII & Doenças da Pele e Tec. Celular Subcutáneo & 810 & 6.08 \\
VI & D. do Sistema Nervoso e dos Sentidos & 773 & 5.80 \\
V & Transiomos Mentais & 574 & 4.31 \\
I & Doenças Infecciosas e Parasitárias & 417 & 3.13 \\
III Neoplasmas & 206 & 1.55 \\
III & D.Gl.Endócr.,Nutr.,Metab. e Tr. Imunitários & 153 & 1.15 \\
Xi & Compl. da Gravidez, Parto e Puerpério & 77 & 0.58 \\
IV & Classificação Suplementar & 53 & 0.40 \\
XIV & D. do Sangue e Orgäos Hematopoiéticos & 36 & 0.27 \\
Algumas Afecçōes Orig. no Per. Perinatal & 6 & 0.05 \\
\hline & TOTAL & 13328 & 100 \\
\hline
\end{tabular}

Segundo Wilkings Jr., "...o projeto e funcionamento de qualquer pronto-socorro constituem o produto de vários fatores, sendo os principais a demanda pública e o compromisso da administraçāo hospitalar de satisfazer as necessidades da comunidade ${ }^{m b}$. Quanto a estes aspectos, nossos achados podem auxiliar a administraçāo do HUSM, fornecendo subsidios para tornar o SPA mais capacitado do ponto de vista ffsico, funcional e humano a atender sua real demanda.

Felipe Jr. enumera muito bem as qualidades que deve ter um médico socorrista, comentando em nosso meio a falta de especialidade Socorrista ${ }^{5}$, profissional responsável pelo tratamento de pacientes que procuram o pronto-socorro, médico este que deveria ter grande experiência.

O comum, porém é terem os serviços de pronto-socorro $\mathrm{o}$ atendimento feito por médicos recém-formados, geralmente sem experiência maior em Medicina de Urge̊ncia e muitas vezes ligados a uma especialidade, sem a formaçāo de médico geral. Isto é fruto de uma estrutura de ensino que vem sendo alvo de publicaçōes que diagnosticam as falhas na formação de médicos no Brasil ${ }^{1,7}$.

No HUSM, acresce-se a isto o fato de nāo haver docentes do Curso de Medicina no SPA, ficando a orientaçāo docente dos alunos a cargo dos médicos plantonistas, que são médicos contratados pelo HUSM.

$O$ relacionamento entre médico plantonista e aluno fica baseado na troca de utilidades: o aluno ajuda o médico diminuindo-lhe os afazeres e em troca recebe orientaçāo. É Í́gico que diante deste quadro o aprendizado nāo é o ideal, mas é o que se dispōe no momento, havendo muito por fazer para melhorá-lo.

Os achados são utilidade ainda para se planejar uma melhor preparaçāo dos alunos para atender no SPA, seja através de seminários, aulas, elaboração de rotinas etc.

O próprio currículo de Clínica Médica deve ser analisado à luz destes achados, adaptando-se mais à realidade de nosso meio.

\section{Summary}

The authors analised the written reports of the internship students on duty on the first-aid clinic of the HUSM, from January 1984 to December 1985. The chapters of International Diseases Classification with the highest incidence were "Respiratory Tract Diseases" (2055 cases, 15,42\%), "Sintomas, Signes and III-deffined Affections" (1951 cases, 14,64\%), "Lesions and Poisonings" (1701 cases, 12,76\%), "Circulatory Tract Diseases" (1247 cases, 9,36\%).

Acute respiratory infections (1120 cases, 8,40\%), hypertension (508 cases, $4,35 \%$ ) and non psicotic mental disturbances (522 cases, 3,92\%) were the most frequent diseases.

Each intern spent about $13,87 \mathrm{~h}$ on duty per week.

The greatest part of the consultations were not urgent, so many diagnosis were poorly defined. The authors analised these factors implying that the interns need a better orientation on emergency service medicine, as well as that this service needs to adequate to the local reality.

\section{Referências Bibliográficas}

01. ASSOCIAÇĀO BRASILEIRA DE EDUCAÇĀO MÉDICA. Preparação do médico geral. Rio de Janeiro, ABEM, 1983 (Série Documentos da Associação Brasileira de Educaçāo Médica, n.5).

02. BRASIL. Ministério de Educaçāo e Cultura. Conselho Federal de Educaçāo. Resoluçāo n.9 de 24 de maio de 1983. D.O.U. de 30/05/85.

03. BRASIL. Ministério de Educação e Cultura. Secretaria de Educação Superior. Manual do Internato 1984. p.13 (Série de cadernos de Ciências da Saúde, n.7). 
04. CLASSIFICAÇĀO INTERNACIONAL DE DOENÇAS. Porto Alegre, Sagra S.A. Editora e Distribuidora, 1981.

05. FELLIPE Jr., J. de. O médico e o paciente no Serviço de Emergência. In: Pronto Socorro Fisiopatologia, Diagnóstico e Tratamento. Rio de Janeiro, Guanabara Koogan S.A., 1983. Cap.l, p.1-2.

06. GROSS, P. L. \& FOX, S. S. A triagem do Serviço de Emergência. In: Pronto Socorro: Fisiopatologia, Diagnóstico e Medicina de Urgência. Rio de Janeiro, Guanabara Koogan S.A., 1982 (ediçāo em lingua portuguesa).
07. SOUZA, Carlos A. M. de. Ensino de Clínica Médica. In: CONGRESSO BRASILEIRO DE EDUCAÇĀO MËDICA, 4. Belém, 9-12 nov. 1977. Anais... Belém, ABEM, 1977. p.21-7.

08. WILKINGS Jr., Earle W. Planejamento e Operação do Pronto Socorro. Rio de Janeiro, Guanabara Koogan S.A., 1972. Cap.33, p.631-40 (edição em lingua portuguesa).

Endereço dos autores:

Rua Floriano Peixoto, 1394

97100 - Santa Maria - RS 